\title{
KANSAS CITY AREA LIFE SCIENCES INSTITUTE
}

\author{
William G. Brundage \\ Executive Director
}

The Life Sciences Initiative is an economic development initiative. If Kansas City is to prosper in the future, it has to address the infrastructure requirements of the $21^{\text {st }}$ Century. Today, economies are regional and if a region does not posses a significant "technology" infrastructure within the next five to ten years, it will not be in a position to compete. The Kansas City Area Development Council and the Civic Council of Greater Kansas City established a Life Sciences Task Force which determined that the Life Sciences could provide this region with a competitive edge. A tectonic shift has occurred in the world economy. Strong arms and legs, a good work ethic, a central location, a low cost business climate, and access to materials and transportation will no longer be sufficient for a region to compete. Rather, competitive advantage will be defined by a combination of traditional factors that equate to financial capital, and nontraditional factors $\nabla$ expertise and knowledge $\nabla$ that equate to intellectual capital. The regions that succeed in balancing this new equation will prosper into the future by expanding their economies and creating new value, wealth, capital, and profit through marketing products of the mind.

The Life Sciences Task Force determined that in order to attain its vision of Kansas City as "A nationally known center of established, worldclass life sciences companies, private and academic research institutions, and emerging, entrepreneurial companies in a community recognized for its opportunity and attractive quality of life," the community will have to do the following:

> Make a major financial investment in Kansas City's institutions of higher education.

$>$ Build the physical and organizational support structure for life sciences entrepreneurs.

$>$ Develop, finance, and commercialize intellectual products in Kansas City.

$>$ Attract the brightest scientific talent and the best, young entrepreneurial companies that can be found.

This past Spring the sponsoring organizations created the Life Sciences Institute and assigned it the following functions: 
$>$ Accountability

$>$ Evaluation

$>$ Oversight

$>$ Resource Allocation

$>$ Collaboration

$>$ Fundraising

$>$ Lobbying

$>$ Marketing

The first order of business was to develop a business plan, which will be completed by the end of August. This plan is concentrated around the following focus areas:

$>$ Human Development and Aging

$>$ Cancer

$>$ Cardiovascular Diseases

$>$ Neurological Diseases

$>$ Infectious Diseases

Plans for commercialization, economic development, and educational support will be included. Our goal is to develop a ten-year investment strategy that will enable the Area's research institutions to collectively attain $\$ 500$ million annually in Research and Development expenditures.

How do we determine Kansas City's niche? The competition is considerable and we will not be able to compete in every field. In order to make the best possible investment decisions, we are employing the following: an external Scientific Advisory Committee and a process called "business dynamics modeling." The Committee will advise us on the science and where they believe we can be competitive. The business dynamics modeling will show us what it will take to achieve the goal of $\$ 500$ million in annual $R \& D$ expenditures.

The business plan will be presented to the boards of directors of the Kansas City Area Development Council and the Civic Council of Greater Kansas City for approval on September 8, 2000. Fund raising will begin shortly thereafter. 